\title{
RELATO DE EXPERIÊNCIA: \\ UM ENSAIO SOBRE OS DESEJOS NA LINGUAGEM
}

Rafaela Queiroz Ferreira Cordeiro é formada em Jornalismo e Letras, com mestrado em Linguística pela Universidade Federal de Pernambuco (UFPE) e doutoranda em Linguística pela mesma instituição. No momento, finalizou o doutorado sanduíche na Universidade de Guelph no Canadá. É bolsista da CAPES - Proc. n. BEX 2310/14-7 - e transita pelas áreas de Linguística, Jornalismo, Literatura e Psicanálise. E-mail: rafaelaqueirozcordeiro@gmail.com .

\section{Resumo}

O objetivo deste ensaio é fazer uma reflexão sobre os desejos na linguagem, a partir do relato da primeira experiência de uma estudante brasileira de Linguística durante o Doutorado Sanduíche no Canadá - iniciado em junho de 2014 e finalizado em maio de 2015 - sob a supervisão do Prof. Dr. Clive Thomson.

\begin{abstract}
The purpose of this essay is to make the reader think about the desire in language, from the report of the first experience of a Brazilian student during her split-site Linguistics $\mathrm{PhD}$ program in Canada — started in June 2014 and ended in May 2015 - under the supervision of Prof. Dr. Clive Thomson.
\end{abstract}

Em junho de 2014, dei início a uma experiência em um país outro. Como estudante de Linguística, viajei para o Canadá cheia de desejos: desejo de falar "bem" um idioma que não é meu, desejo de saber identificar um "bom" corpus para analisar, desejo de escrever uma "boa" tese, desejo de mostrar-me uma "boa" aluna a um sujeito que nunca me viu na vida. E a lista não para por aqui. Os desejos foram e são ainda muitos. Eles manifestaram-se — e ainda se manifestam - numa ansiedade incontrolável que aparecia para mim sob os efeitos daquilo que a convenção socialmente diz e nos impõe como sendo a representação favorável do "bom" aluno. Discursos que circulam e se alimentam e, por isso, mantêm o status quo dessa imagem. E desse desejo do bom, vieram - e ainda vêm - as faltas: de não falar o inglês que eu desejei falar; estar num impasse metodológico diante de um corpus que não se cala e, ainda assim, não me convence; de uma escrita ainda "capenga", incerta e lacunar; e de não poder estar à altura daquilo que havia prometido. Foram e são muitos os desejos que se desencontram. E se não fossem esses, seriam outros. É este investimento do desejo e esta iminência da falta - uma falta que, embora indique uma ausência de uma ausência, é sempre presente - que reveste o universo simbólico da linguagem (LACAN, 1998a, p. 277).

Para ilustrar essa falta, cuja linguagem parece nunca "preencher", trago o relato desta experiência, não incomum a muitos alunos que embarcam na jornada de um doutorado sanduíche ou estágio no exterior: no primeiro dia que fui à Universidade de Guelph, o meu professor, Clive Thomson, solicitou que cada um se apresentasse aos colegas de classe. E embora já tenha vivido a experiência de me apresentar a um grupo de estranhos diversas vezes na minha vida, presenciei ali uma ausência de uma falta, isto é, uma dupla angústia, não alheia aos desejos: o de falar um idioma que não é a minha língua dita materna e o de apresentar-me de forma adequada aos meus colegas de classe. Nesse momento, deparei-me com duas questões: o que significa falar "bem" um idioma que não é a sua língua nativa? e como apresentar-me de forma agradável a um outro com quem nunca me relacionei? Não sei se é porque a minha relação com a vida acadêmica se deu sempre pela via afetiva, mas aquele instante forneceu rico material 
para pensar sobre como nós nos constituímos sujeitos: plenos de desejos, nós agimos sempre tendo em vista aquele outro, o olhar desse outro, "não tanto porque o outro detenha as chaves do objeto desejado, mas porque seu primeiro objeto é ser reconhecido pelo outro" (LACAN, 1998a, p. 269, grifo nosso). Ou seja, não há como não nos concebermos fora desse espaço do desejo que vem do outro e por intermédio do reconhecimento desse outro. A imagem da mãe à espera do seu bebê esclarece um pouco o funcionamento do desejo no terreno da linguagem: o filho que a mãe gera não é apenas um ser físico; a espera é preenchida pelo desejo. Isso significa que é o desejo que o gera e o nome que ela lhe dá que o estruturam e o ancoram no Real (LACAN, 2002, p. 41). E assim vamos nos constituindo como sujeitos sociais, pulsionais, que se dirigem ao apelo de um outro, mas cujo retorno nunca satisfaz. É esse outro com o qual nos relacionamos que abre as portas para um incessante espaço do desejo - dizemos incessante, pois o desejo do homem nunca se conforma.

A esse exemplo, trago Bakhtin (1993, 1997a, 1997b, 2005), Bakhtin e Volochinov (2006) e Lacan (1998a, 1998b). Estes pensadores fornecem material não apenas para uma pesquisa; de fato, aproximar-me deles traz um conforto para a minha vida vivida. Aquela experiência, embora não tenha sido a minha primeira nem a minha última apresentação a um grupo de estranhos, é única, singular, concreta, dotada de uma memória - seja um já-dito trazido de experiências anteriores, seja um já-dito que a situação comunicativa (o gênero discursivo) carrega. E situar essa experiência no contexto social que a gerou, como fizemos acima, é relevante porquê, como muito bem expõe Bakhtin (1997, p. 279-289), a comunicação se realiza em gêneros, os quais são construídos nas diferentes esferas das atividades humanas e se caracterizam por apresentar uma temática, um estilo e um tom composicional. Como toda produção de linguagem está ligada a uma atividade humana, há tantas formas de gêneros quanto atividades.

Nessa mesma perspectiva, trago o que Bakhtin e Volochinov (2006, p. 127) afirmam sobre o discurso. Embora existam muitas controvérsias sobre a autoria da obra Marxismo e Filosofia da Linguagem, a qual me refiro, como esse debate não pertence à discussão estabelecida neste relato, faço a referência ao livro conforme as edições publicadas no Brasil. Assim, para esses dois pensadores russos, o discurso, produzido por cada um de nós na relação com o outro, instaurada por meio da linguagem, é apenas um elo de uma corrente verbal ininterrupta que retoma já-ditos e antecipa discursos futuros. No entanto, essa mesma memória não necessariamente facilita o ato da apresentação, pois, mesmo que essa fosse parte da minha profissão ou a minha tarefa diária - casos em que há uma maior "familiarização" com o gênero —, a enunciação de quem eu sou para aqueles outros nunca é total. Ora, a verbalização total é impossível não apenas porque nos inserimos no grande diálogo da vida vivida - ao qual Bakhtin se refere em sua obra Para uma filosofia do ato (1993, p. 19-20) como um evento incompleto, em processo -; mas também porque o sujeito "escorrega" na impossibilidade de preencher tudo aquilo que ele acha que falta no dizer. Só que, como nos esclarece Lacan (1998a, p. 276-277), há ausências que o Simbólico não nos permite alcançar; portanto esses vazios que acreditamos poder preencher não podem ser 
colocados em significantes, palavras. E isso faz parte da própria limitação da linguagem: como somos sujeitos fundamentalmente de linguagem, somos sujeitos com traumas.

Se pararmos alguns minutos para pensar na maneira como a realidade se apresenta para os animais e o homem, notaremos que é a presença da linguagem que realiza o real fundamentalmente por outra via: é através da ordem do Simbólico, estabelecida pelo significante, que o nosso corpo se inscreve. Desse modo, o corpo não é apenas matéria física: estruturado pela linguagem, a construção dele exige uma perda - a perda simbólica do falo. E o acontecimento dessa falta no registro do simbólico é, portanto, decisivo na estruturação do sujeito (LOBOSQUE, 2001, p. 68-69). Assim, quando nos deparamos com a situação comunicativa apresentação a um grupo de estranhos, nós passamos a produzir uma grande quantidade de significantes em uma tentativa de nos definir, identificar e agrupar. Ora, esse dizer que diz sobre nós mesmos para os outros e, em retorno, para nós mesmos, nunca parece ser suficiente. Por mais que tentemos nos descrever, marcando o nosso espaço axiológico no dizer, o ato de identificarmo-nos a partir do emprego de determinadas expressões ao invés de outras é um ato avaliativo que responde sempre a alguma coisa: ao apelo desse outro, ao olhar que ele nos lança, ao enunciado que se abre a uma resposta. Isso acontece quando nos deparamos também com um objeto que, mesmo sabendo o que é, às vezes nos faltam palavras para o caracterizar. E por mais que o tentemos explicar, alguma coisa parece ser deixada de fora como se não pudesse ser "colocada" em palavras: este algo que está "lá", no grande Outro, no Real, em um plano "extra-linguístico", vai além do que podemos articular. Pois, para Lacan (1953/1955 apud EVANS, 1996b, p. 162-163), o Real é o registro que representa o irrepresentável da língua e o que não cessa de se inscrever nela: "o real é ou a totalidade ou o instante esvanecido" (LACAN, 2005, p. $45)$.

Desse modo, a linguagem, além de social, histórica - porque atravessa e carrega a memória do já-dito - axiológica e dialógica (BAKHTIN, 2005, p. 55-56), sempre é marcada por uma falta, um vazio que também constitui o sentido. Naquele momento em que fui me apresentar, eu só pensava em como "forjar" esse vazio a partir de uma língua que não é a minha primeira. E, baseado nisso, eu só achava que a minha fala apresentaria uma maior evidência dos meus desejos, das minhas faltas, porque o inglês se apresenta a mim como uma língua outra. Mesmo tendo pistas do horizonte social partilhado por alguns alunos, os quais eram latino-americanos, falantes do espanhol, a intranquilidade permanecia e o meu corpo respondeu ao apelo da sala a partir de alguns enunciados que, marcados pelo tom da insegurança e do nervosismo, respondeu contrariamente ao meu desejo, ou melhor, a seu favor: o desejo de falar "bem" uma língua estranha, estrangeira, mas já familiar, foi atropelado por um falar que insistia não poder se realizar porque criava no meu corpo um eco de uma falta. E, logo após, o meu desejo era que aquele evento único, irrepetível, do qual fiz parte, fosse possível de ser apagado e "reescrito". Todavia, mesmo que este se repetisse minutos depois, no mesmo espaço físico diante daqueles mesmos outros, cada ato é uma criação singular, orientada para o objeto e direcionada a um outro, vinculada a um contexto 
social e momento histórico (BAKHTIN, 1993, p. 19-21); embora possa compartilhar com outros atos elementos comuns, como, por exemplo, a materialidade da língua.

Portanto, a partir do relato dessa experiência, a qual não é indiferente para a maioria de nós, é possível apontar, mesmo que provisoriamente, algumas considerações finais a partir do que expõem esses teóricos, os quais, por sua vez, abrem a nossa perspectiva de lidar com as vivências. Dizemos provisoriamente porque a teoria não deixa de ser uma forma de entender como estamos vivendo as nossas experiências. Todavia, destaco que o trabalho de interpretação, reflexão ou atribuição de sentidos à vida que está sendo vivida insere-se num movimento aberto e ininterrupto de construção e nunca de finalização. Desse modo, em uma tentativa de, por ora, concluir este relato, recupero alguns pontos já levantados para nos ajudar a pensar sobre as relações que estabelecemos com uma língua que é ou "parece" outra.

Ora, falar uma língua outra não se resume àquela do estrangeiro, como se em contraposição à nossa língua dita materna. Como bem analisa De Nardi (2009, p. 187188), há inclusive sujeitos que se sentem mais acolhidos na língua estrangeira do que em sua própria língua. Isso se dá porque os sujeitos, por serem heterogêneos, lidam com a língua e a cultura de forma diversa. Aquela, longe de ser transparente e homogênea, é atravessada pela história e pelos discursos - muitos vinculados aos valores consagrados como dominantes; mas nela também circulam aqueles outros discursos que permitem espaços de não-identificação e diferentes processos de subjetivação. Mas, além da heterogeneidade nossa, há um espaço da língua que, ao se estruturar no Real, não nos é possibilitado ter acesso. E essa impossibilidade envolve qualquer língua e não necessariamente a do falar a língua do outro. Por isso, no espaço da nossa própria língua, há o que Lacan (1998b, p. 100-103) chama de lalangue, a saber, o confronto com a iminência do não-acerto, furo que, muitas vezes, é por nós "notado" através de um desentendimento com o outro numa situação de comunicação. Esse não acesso ao Real da língua se dá porque somos estruturados na falta e a partir dela. E é nessa ordem que se inscrevem os nossos desejos inconscientes, os espaços dos discursos desejantes.

Há um aforismo psicanalítico que diz o seguinte: todo desejo é desejo do Outro. Isto não quer dizer apenas que eu só quero aquilo que o Outro tem, no sentido da competição, ou da inveja; quer dizer também, e sobretudo, que eu só posso desejar a partir de um lugar aberto pelo desejo do outro [...] É deste lugar impossível — pois não há outro - que o desejo de cada um se constrói: o desejo é desejo do Outro justamente porque não oferece respostas exatas ao que o outro espera ou exige, não preenche o que falta ao Outro - e sim reproduz a marca da pergunta, da busca, da inquietação de todo desejo. O desejo humano é, portanto, um desejo que não se conforma... que pode aceitar aquilo que vem do Outro quando se trata de uma interpelação ou de um convite, jamais como ordem ou imposição (LOBOSQUE, 2001, p. 75).

Assim, entre a língua e a falta acabamos voltando inevitavelmente aos desejos; ou, talvez, entre os desejos e a língua, chegamos às faltas. De qualquer maneira, há um jogo que falta ao sujeito: esses desejos — os "meus", os "seus" e os "nossos" — levamnos sobremaneira aos outros, ao relacional, à alteridade que instaura o diálogo. Por isso, 
no espaço do que é familiar, do já falado, da língua dita materna, o sujeito também se depara com discursividades que permitem-no falar a partir de um espaço outro, daquele que é desejado ou da imagem "refletida" do que é idealizado. E isso se dá desde o momento em que nascemos, quando a mãe representa o Outro primordial, aquele que está satisfazendo os desejos do filho e dando sentido a eles (LACAN, 1957/1958 apud EVANS, 1996a, p. 38). É através da boca da mãe e dos seus próximos que o homem atribui sentido às suas vivências, constituindo-se como sujeito. Esse outro que nos permite ingressar nos discursos é ponto central também na obra de Bakhtin (1993, 1997a). Partindo da perspectiva sócio-histórica da linguagem, sem considerar a noção do inconsciente tão cara à psicanálise, o teórico russo destaca também as relações sociais, a alteridade, os outros como o ponto de partida, o primado da constituição do homem na vida vivida:

Tudo o que me diz respeito, a começar por meu nome, e que penetra em minha consciência, vem-me do mundo exterior, da boca dos outros (da mãe, etc.), e me é dado com a entonação, com o tom emotivo dos valores deles. Tomo consciência de mim, originalmente, através dos outros: deles recebo a palavra, a forma e o tom que servirão para a formação original da representação que terei de mim mesmo. Elementos de infantilismo na autoconsciência ("Será que mamãe gostaria de mim assim...") às vezes persistem até os nossos últimos dias (a percepção e a representação de si, do próprio corpo, do próprio rosto, do seu passado, num tom enternecido). Assim como o corpo se forma originalmente dentro do seio (do corpo) materno, a consciência do homem desperta envolta na consciência do outro (BAKHTIN, 1997a, p. 379).

Então, o homem não existe fora da relação com o outro, que, por sua vez, se dá por meio da linguagem. O entorno, a forma, o desenho da silhueta de cada um é construído discursivamente no encontro social e histórico com outra consciência. Todavia, este processo, iniciado a partir do nascimento, continua a se repetir por toda a nossa existência. Ora, as palavras se apresentam à nossa consciência linguística não como um "sistema abstrato de formas normativas" (BAKHTIN; VOLOCHINOV, 2006, p. 97). Pelo contrário: os nossos enunciados são elaborados a partir das palavras dos outros (BAKHTIN, 1997b, p. 311-312). Talvez por isso que as lacunas e incompletudes do dizer pareçam ser mais evidentes numa língua estrangeira que na dita materna porque, como afirma De Nardi (2009),

a complexidade do estar na língua do outro é a do trabalho de um sujeito que terá de se enfrentar com suas próprias memórias - discursivas memórias - sobre a sua língua, dita materna, e a língua do outro, dita estranha. Trata-se de um trabalho com as resistências do sujeito, mas que também pode levar à encantadora descoberta que pode estar nessa estranha língua, um espaço de outras/ novas memórias. [...] Nesse trabalho de "aderir" (ou não) à língua do outro entram em funcionamento mecanismos inconscientes e ideológicos que representam para o sujeito, atravessado por essas ordens, a articulação entre o social e o individual (DE NARDI, 2009, p. 187).

Embora a experiência de não-pertencimento que senti naquela situação de comunicação tenha se rompido no encontro com uma língua dita estrangeira, isso me 
fez chegar "perto" - no sentido de uma sensação apenas - do Real enquanto a nãopossibilidade de me dizer, simbolizar. Só que, ao mesmo tempo que isso se deu, percebi que muito além daquele idioma, eu já experimentava na minha língua dita primeira um deslizamento constante, uma prolixidade e inegável ambiguidade na construção dos sentidos, tal como retomam muitos dos meus "interlocutores". Percepção esta que já experimentava antes da leitura desses teóricos e que apresentava-se com muito desconforto, o qual, inclusive, não desapareceu por completo. E, talvez, nunca há de acontecer. No entanto, foi só a partir do que expõem os teóricos supracitados que passei a refletir sobre o lapso, atropelo, a ambiguidade, não como o lugar majoritário do erro. Contrariamente ao que tinha aprendido no meu curso de comunicação, penso hoje que a língua é mais o espaço do (des)entendimento. Saber então da opacidade e heterogeneidade da língua (AUTHIER-REVUZ, 1982, p. 21) permitiu que eu me aproximasse de como os meus discursos se operam - ou não - no cotidiano. E isso, para mim, como estudante de Linguística, trouxe muitos desafios; em especial porque estudar com mais profundidade o campo da Linguística não significa necessariamente que vamos ter um domínio e controle maior sobre os nossos dizeres.

E, mesmo que Bakhtin não fale em inconsciente, o russo apresenta a ideia de um sujeito heterogêneo, que se constitui na vida vivida, na experiência, e que não está completo. Já Lacan aponta o sujeito como estruturado numa dupla ausência, dupla angústia, que está lá, na ordem do impossível, do Real, muito além de poder ser significado. Essas duas concepções sobre o sujeito não estão em necessário desacordo; por isso que, antes de vê-las como dicotômicas, trago-as como noções que podem ser operacionalizadas em conjunto - sem promover uma homogeneização das ideias dos dois teóricos - ampliando o olhar sobre a nossa análise.

Portanto, foi a partir dessa língua dita outra que me deparei com os outros espaços da minha língua; foi na imersão em uma língua e cultura dita outra que descobri resistências, angústias, discursos e espaços de identificação estabelecidos sóciohistoricamente pela minha própria língua; mas que insistentemente acreditava pertencer ao entrave com essa língua outra. E esses conflitos se estabeleceram e continuam a se estabelecer metonimicamente na relação com os meus desejos, porque entre o desejo de ser compreendido e o de dizer o que quero (ou acho que quero) dizer há a porção do que não pode ser dito, do indizível, que é de várias ordens: da língua, do Real, do sujeito, da história, da memória, do social. Reconhecer, portanto, que o dizer é constitutivamente marcado pela ausência de um dito que não se completa, por mais saturado de significantes que se apresente, é considerar também que não há o "bem" falar de um idioma. Isso faz parte de uma das inúmeras barreiras que impomos a nós mesmos, através do Outro, da sociedade, que nos vigia, nos pune com os certos e os errados, e, não menos, oferece-nos pequenas doses de satisfações. Nunca estaremos satisfeitos com as escolhas que fazemos, pois somos por natureza seres incompletos. Existe e existirá sempre um espaço a desejar que, de alguma maneira, aparece nos entremeios entre o dito e o não-dito, no corrigir um dizer que insiste em aparecer na fala, nos esquecimentos, lapsos, desvios, nas ambiguidades, nos (des)entendimentos. 


\section{Referências}

AUTHIER-REVUZ, Jacqueline. Heterogeneidade mostrada e heterogeneidade constitutiva: elementos para uma abordagem do outro no discurso [1982]. In: Da mesma autora. Entre a transparência e a opacidade: um estudo enunciativo do sentido. Porto Alegre: EDIPUCRS, 2004, p. 11-80.

BAKHTIN, Mikhail M. Apontamentos 1970-1971. In: Do mesmo autor. Estética da criação verbal. Tradução feita do francês por Maria Ermantina Galvão G. Pereira. 2. ed. São Paulo: Martins Fontes, 1997a, p. 369-398.

BAKHTIN, M.; VOLOCHINOV, V. Marxismo e filosofia da linguagem. Problemas fundamentais do Método Sociológico na Ciência da Linguagem. 12. ed. São Paulo: Hucitec, 2006.

BAKHTIN, Mikhail M. Os gêneros do discurso. In: Do mesmo autor. Estética da criação verbal. Tradução feita a partir do francês por Maria Ermantina Galvão G. Pereira. 2. ed. São Paulo: Martins Fontes, 1997b, p. 277-326.

Para uma filosofia do ato. Tradução livre para fins acadêmicos de Carlos Alberto Faraco e Cristovão Tezza. Prefácio de Michael Holquist, 1993.

Problemas da poética de Dostoiévski. Tradução de Paulo Bezerra. 3. ed. Rio de Janeiro: Forense Universitária, 2005.

DE NARDI, Fabiele Stockmans. Entre a rejeição e o acolhimento na língua do outro. Revista do Programa de Pós-Graduação em Letras da Universidade de Passo Fundo, v. 5, n. 2, jul./dez. 2009, p. 182-193.

EVANS, Dylan. Desire. In: Do mesmo autor. An introductory dictionary of Lacanian psychoanalysis. London and New York: Routledge, 1996a, p. 36-39.

Real. In: Do mesmo autor. An introductory dictionary of Lacanian psychoanalysis. London and New York: Routledge, 1996b, p. 162-164.

LACAN, Jacques. Função e campo da fala e da linguagem em psicanálise. In: Escritos. Tradução de Vera Ribeiro. Rio de Janeiro: Jorge Zahar Ed., 1998a, p. 238-324.

Lição 2 (19 de novembro de 1958). In: Do mesmo autor. O desejo e sua interpretação. Publicação não comercial. Circulação interna da Associação Psicanalítica de Porto Alegre, 2002, p. 35-51.

O simbólico, o imaginário e o real [1953]. In: Do mesmo autor. Nomes-do-Pai. Tradução de André Telles. Revisão Técnica de Vera Lopes Besset. Rio de Janeiro: Jorge Zahar Ed., 2005, p. 9-53.

On Feminine sexuality: the limits of love and knowledge. Book XX [Encore 1972-1973]. Edited by Jacques-Alain Miller. Translated with notes by Bruce Fink. New York and London: W.W Norton \& Company, 1998 b. 
LOBOSQUE, Ana Marta. Experiências da loucura. Rio de Janeiro: Garamond, 2001. 